\title{
Sobre um caso de Hematometra Secundario
}

\section{Trabalho lido na Sociedade Arnaldo v. de Carvalho.}

E' com grande prazer que vos venho apresentar um caso de hematometra, recentemente observado na Clinica Gynecologica do Hospital Central da Santa Casa, a cargo do illustre Professor Dr. N. Moraes. Barros, e da qual tenho a honra de ser um dos internos.

Escolhi este caso não só pela sua extrema raridade, mas tambem pelas causas etiologicas especiaes qu eo produziram e pelo interesse pratico que proporciona áquelles que se dedicam á Gynecologia.

Como sabeis, o hematometro ou hematometrio é constituido pelo accumulo de sangue menstrual na cavidade uterina em virtude de um obstaculo existente no canal cervical, impossibilitando o seu escoandento natural para o exterior.

Era essa a gynecopathia que apresentava a senhora M. C., com 45 annos de idade, casada e residente nesta Capital, ao entrar no Serviço de Gynecologia em 12 de Agosto deste anno. Trata-se de uma mlulher bem constituida, relativamente magra, apparentando bôa saude. Quanto aos seus antecedentes pessoaes e de familia, nada nos informa digno de registro, e gaba-se de ter gosado sempre bôa saude, tendo sido apenas acommettida de variola, quando creança. Quanto ao seu passado obstetrico nos refere ter tido 12 partos á termo e anteriormente a estes dois abortos, respectivantente de $2 \frac{1 / 2}{2}$ e 3 mezes. expontaneos. Os puerperios foram bons, salvo o ultimo que decorreu ligeiramente febril, prendendo-a no leito por espaço de 15 dias.

Antecedentes genitaes: a menarcha se intallou aos 14 annos de idade. Seu cyclo menstrual, irregular quando solteira, em nada se modificou após o casamento. A quantidade do sangue catamenial perdida é regular, variando a duração do periodo menstrual entre 5 e 10 dias. As suas regras se processam com intervallos de um mez, sobrevindo tambeml, não muito frequentemente, duas vezes no mesmo mez. O sangue que perde é vermelho, liquido e sem mau cheiro. 
A sua vida genital decorreu sem qualquer anormalidade até Agosto de 1918, época em que se processou o seu ultimo parto, o qual foi laborioso e terminou com uma applicação de forcipe, nascendo o feto. Quinze dias de puerperio febril se sucoederam, deixando como vestigio um corrimento amarello, pouco abundante, viscoso e fetido, que perdura durante o repouso menstrual e do qual a paciente nunca se tratou.

Desde então até a sua entrada no hospital, isto é, por um espaço de quasi 7 annos, começou a sentir, em cada periodo pre-menstrual, dôres no baixo ventrie que se intensificavam gradativamente a medida que se processava o catamenio e a ter uma sensação de tumor no hypogastro, soffrimentos que se attenuavam por completo uma vez installado o fluxo catamenial. Assim tem succedido mensalmente até 10 de Junho p .p., data do seu ultimo catamenio, cuja duração foi de 5 dias.

Amenorrheica de 2 mezes procurou o hospital em 12 ide agosto informiando que, de ha 20 diạs, as suas dôres habituaes tinham se exacerbado, a ponto de se tornarem intoleraveis, acompanhadas de nauseas ,vomitos e vertigens, mas apyreticas.

\section{EXAME GYNECOLOGICO, FEITO PÉLO PROF. MORAES}

\section{BARROS EM 13 DE AGOSTO 1925:}

A inspecção do ventre é negativa .A' palpação encontra-se, na região hypogastrica mediana, uma resistencia globulosa que attinge a 3 dedos transversos da cicatriz umbellical, um pouco mais desenvolvida para a esquerda do que para a direita da linha mediana. Essa resistencia dá impressão de um tumor regularmente espherico, de superficie lisa, consistencia elastica, pouco sensivel, movel e aprofundando-se na escavação pelvica.

Os orgãos genitaes externos são normaes; a mucosa vestibular é de aspecto normal, ligeiramente descorada, Vulva entreaberta e permeavel para mais de 2 dedos. Ao longo da parede vaginal anterior,, uma resistencia elastica, de superficie lisa, que faz forte saliencia no lumem vaginal e enche a escavação, apagando por completo os fundos de saccos anterior e lateraes. Não se encontra collo uterino, o 
qual apenas se deixa reconhecer por uma, ligeira irregularidade da mucosa vaginal, na superficie do tumor. Reconhece-se ainda pelo toque que o tumor pelvico corresponde ao tumor descripto pela palpação do ventre, tem o volume aproximado de uma cabeça de feto, é movel e pouco sensivel. Regióes dos annexos livres. Ao especulo se verifica que o collo, inteiramente apagado, se reduz á ligeira irregularidade na mucosa, constatada pelo toque ,no centro da qual existe uma depressão punctiforme correspondendo evidentemente ao orificio externo completamente atresiado.

No dia 14 de agosto, após anesthesia por chloretyla, foi operada pelo Professor Moraes Barros.

Processo operatorio: applicada as valvulas vaginaes, após. rigorosa asepsia fixou-se a mucosa vaginal, de um e de outro lado, junto ao orificio externo atresiado do collo e conseguiu-se, por meio do hysterometro. vencer a resistencia da atresia penetrando immediatamente no cavum uterino, do qual começou a escoar-se sangue de aspecto e consistencia xaroposa, de côr escura semelhante ao alcatrão. Ampliada essa abertura por meio de pequenas incisões irradiadas do seu contorno, fez-se a dilatação por meio de vellas de Hegar até o n." 12, completando-se assim o esvasiamento do sangue retido, cuja quantida.de era de 350 c. c.. Vierificou-se que a atresia interessava tão somente o orificio externo e cerca de meio centimtro do canal cervical a elle contiguo. Tamponou-se a cavidade uterina com gaze iodoformada.

O periodo post operatorio foi optimo. A doente teve alta, completamente restabelecida, em 18 de agosto.

\section{DISCUSSÃO}

Como acabaes de ver, o diagnostico se impoz pela sua symptomatologia caracteristica, comprovada pelo exame somatico. Pela simples anamnese podiam ser os symptomas compativeis com outras hypothese $_{s}$ - gravidez topica, kysto do ovario com torsão do pediculo. A primeira foi excluida por não apresentar a paciente nenhum 
outro signal de gravidez a não ser a amenorrhea de 2 mezes; ademais ha quasi 7 annos não concébe e está no inicio da mlenopausa. Não optamos pela 2. ${ }^{\mathrm{a}}$, porque o tumor que se encontrou era de evolução rapida, acompanhado de dores cuja intensidade era progressiva, symptomas esses desacompanhados de febre, o que não se observa na torsão do pediculo. A hypothese mais plausivel era pois a de hematometra, por estar de accordo com a anamnese colhida e com a dysmenorrhea progressiva que a doente vinha apresentando, em consequencia de uma atresia do orificio externo do collo.

As gynatresias podem ser congenitas ou adqueridas; estas merecem nłais a nossa attençấo por enquadrarem o nosso caso.

Podem ser adquiridas devido a um processo morbido do tracto genital: sarampo, diphteria, typho, que podem trazer ulcerações de que resulta, ulteriormente, a atresia do lumen genital nesse ponto; ou serem ainda a consequencia de molestias exclusivamente genitars: certas vaginites e endometrites purerperaes e outras em que o germen produz necrose da mlucosa e a ferida que se cicatriza por granulação irá produzir a atresia.

Existem atresias adqueridas resultantes de manobras therapeuticas: applicações tcpicas de agentes causticos, physicos e chimicos (chloreto de zinco, nitrato de prata, etc.), ou pelo emprego de uma solução corrosiva, caso o especialista não séja cuidadoso. Ha um processo de tratamento a atmloacusis, que consiste no emprego de um jacto de vapor no cavum uterino, processo que se desmoralizou complesamente por causar uma destruição profunda da mucosa.

\section{ETIOLOGIA DO CASO PRESENTE}

Se mduvida, a atresia, no nosso caso deve ser considerada como produzida por um traumatismo intra-partum, causado talvez pelo forcipe.

Emmet de New-York descreveu soib o nome de dilaceração ou laceração do collo, uma lezão frequentissinła post-partum ou aborto; havendo inffecção a mucosa se inflamma chronicamente, o collo é attingido de metrite parenchymatra; o tecido cicatricial que succede á suppuração da ferida forma um nucleo duro, uma cunha cicatricial, á qual Emmet dá uma extraordinaria importancia na pathogenia de 
certos symptomas. - Foi o que succedeu no presente caso: a atresia foi se processando gradativamente, trazendo sempre dysmenorrhea. que era aggravada pela congestão menstrual e pelo augmento das cellulas da mucosa, diminuindo inda mais o lumen cervical e difficultando o escoamiento do sangue catamenial, que se accumulava na cavidade uterina.

A therapeutica é intuitiva e visa 'o esvasiamento uterino por meio de abertura e dilatação do canal cervical. Devemos todavia fazer dilatações repetidas, de tempos em tempos, para evitar recidivas.

\section{COMPLICAÇÕES}

As mulheres são expostas a serias complicações quando o tratamento é feito muito tardiamente. A collecção pode se abrir expontaneamente no intestino, no estomago, no peritoneo,, mais raramente na vagina.

Noutros casos a collecção se infecta occasionando a pyometria, cventualidade irreductivel porque quasi sempre termina mal, iou pode ainda ser decomposta com producção de gaz septico dando lugar a physometria.

Eram estas as considerações que vos tinha a fazer, não entrando em pormlenores devido á exiguidade do tempo.

\section{Dr. V. Felix de Queiroz}

Assistente da Clinica Gynecologica da Santa Casa 